\title{
PARAFFIN AS PHASE CHANGE MATERIAL FOR THERMAL ENERGY STORAGE, HEATING APPLICATION
}

\author{
"Ghufran G. Shakassi'
}

Nagam O. Kariem ${ }^{1}$
Mohammed J. AliAlatabe ${ }^{1}$

1) Environmental Engineering Department, College of Engineering, Mustansiriyah University, Baghdad, Iraq

\begin{abstract}
Liberally accessible sun based vitality utilization for residential and mechanical applications are ruined since of its discontinuous nature. The thermal energy storage (TES) framework utilizing both sensible and inactive warm has numerous advantages like expansive warm capacity in a unit volume and its isothermal behavior amid the charging and releasing forms. Since of these focal points, in later a long time, a part of investigate work has been going on to overcome issues like moo warm exchange the rates between warm exchange liquid and stage alter fabric (PCM) in both charging and releasing forms of the PCM-based TES framework. In the present experimental investigation results of a combined sensible and latent heat TES system integrated with a varying (solar) heat source is presented. Investigations are carried out in the TES system for different phase change materials (paraffin) by varying HTF flow rates and for various paraffin mass $(2,4$, and 6$) \mathrm{kg}$. Experiments are performed charging processes. The results show that the $2 \mathrm{~kg}$ paraffin mass shows better performance compared to other paraffin mass.
\end{abstract}

Keywords: phase change materials, PCMs, Thermal energy storage, Paraffin, Heating Application.

\section{Introduction}

Lately, due to issues of quick exhaustion of conventional energy sources and ever expanding request of vitality, the implementation of appropriate warm vitality storage is one of the foremost important issues in vitality transformation frameworks. Without a doubt capacity is an important element to progress the productivity of warm vitality utilization in various branches of businesses. In common, there are three sorts for storing the warm vitality: sensible, inactive and thermo-chemical heat or cold storage. Among these vitality capacity sorts, the foremost alluring shape is latent warm capacity in PCMs due to having many valuable properties counting warm source at consistent temperature, heat recuperation with little temperature drop, moo vapor weight at the operational temperature and chemical solidness and non-corrosiveness. There are a few promising advancements going on within the field of PCMs for warming and cooling of buildings.

Numerous creators have detailed the comes about of investigates on PCM warm determinations amid softening and hardening forms in vitality capacity frameworks. Zalba et al. [1] performed a nitty-gritty survey on warm vitality capacity that managed with PCM, warm exchange ponders, and applications. Farid et al. [2] also displayed an audit on the investigation of PCM, airtight embodiment, and application of PCM. Khodadadi and Zhang [3] numerically examined the impact of buoyancy-driven convection on compelled softening of PCM in a circular holder. Theirs comes about appeared that

*Corresponding Author: ghfrangatea@gmail.com 
the rate of softening at the beat locale of a circle is quicker than at the foot locale due to an increment in conduction. Duan et al. [4] tentatively explored the hardening forms of unadulterated n-hexadecane as a PCM interior a rectangular walled-in area based on an enthalpy definition of the vitality condition. The impacts of the cold divider temperature, introductory fluid superheat and viewpoint proportion of the walled in area were examined. It is found that for an walled in area with a bigger viewpoint proportion, the incline of the stage front is limited as it were to the best conclusion of the walled-in area. Khillarkar et al. [5] numerically considered softening prepare of a stage alter fabric in tube geometries of two different setups, (I) square outside tube with a circular tube interior and (II)circular outside tube with a square tube interior. The results revealed that since of the normal convection, warm stratification is gotten within the upper area of the depth. Assis et al. [6] conducted test and numerical considers on dissolving prepare in a circular shell. They give a relationship for the dissolving division versus a fitting combination of the Grashof, Stefan and Fourier numbers. Moreover, they performed another combined exploratory and numerical think about on the hardening of PCM interior a circular shell with different breadths [7]. Tan et al. [8] conducted a test and computational ponders on the softening of PCM interior a circular capsule. They compared the computed and measured temperatures within the best half of the circle point with the steady nature of the liquid fluid layer in that zone. Comes about appeared that the numerical comes about begin to go astray from the test comes about. They found that this minor contradiction may well be related to the warm stratification inside the steady temperature shower that encased the capsule. Medrano et al. [9] tentatively considered warm exchange characterization of five little warm exchangers working as idle warm capacity frameworks amid the charge and release forms. The results indicated that the twofold pipe warm exchanger with the PCM implanted in a graphite framework had the most elevated values. Seeniraj et al. [10] explored transitory behavior of high-temperature PCMs put away in shell and tube warm exchanger. They watched that in case an unfinned tube is utilized, at that point a few amount of PCM closer to the exit of the tube would stay in solid-state. Usually since, closer to the exit, the distinction between heat transfer fluid (HTF) temperature and PCM's melting point would be exceptionally little. Their consideration was focused centered on the plausibility of warm exchange improvement within the warm capacity holder. The results revealed that the channel temperature increment of the HTF leads to diminish within the softening time. It is additionally detailed that lower vitality utilizations, lower values of the mass stream rate of the HTF are required. Vyshak and Jilani [11] numerically analyzed the impact of distinctive configurations of inactive warm capacity (LHTS) having the same volume and surface zone of warm exchange. They displayed a comparative ponder of the whole softening time of a stage alter fabric (PCM) stuffed in three holders of diverse geometric setups: rectangular, cylindrical and shell and tube. Gotten comes about appeared that round and hollow shell holders take the least time for break even with sums of vitality capacity, and this geometric impact is more articulated with an increment within the mass of the PCM [12]. In arrange to improve the warm exchange trade during melting, considered the impact of numerous PCMs with different dissolving temperatures in shell and tube warm exchanger. They used two PCM systems (LHSU2) and single PCM system (LHSU1) during charging prepares and compared the warm exhibitions of the latent heat capacity units [13]. The results revealed that when the mass stream rate was expanded, the two PCM 
framework was effective as it were for least HTF inlet temperature. Subsequently, different PCM unit is more proficient for low values of mass stream rate and channel temperature of HTF.

The aim of this paper is to assess normal convection effects during softening of paraffin wax in twofold pipe warm trade systems. The primary highlight of this ponder is the point by point estimation of the temperature field inside the PCM. The impacts of the channel temperature of HTF on the improvement warm exchange were considered and are reported.

\section{Materials and Methods}

\subsection{Instrument}

An exploratory set-up was outlined and built in arrange to investigate the softening handle of an inactive warm capacity framework. Fig. 1 shows a schematic chart of the exploratory set-up. The PCM store comprised of a $1 \mathrm{~m}$ long even barrel made of $2.5 \mathrm{~mm}$ thick press with internal breadth of $85 \mathrm{~mm}$. A $22 \mathrm{~mm}$ copper tube found centrally within the barrel was the warm exchange tube through which hot water streams to trade warm with the PCM. The outside surface of the PCM holder was well protects by a glass wool of 60 $\mathrm{mm}$ thickness in arrange to avoid warm misfortunes to the surroundings. The framework comprised of a charging circle, which transferred heat from the hot water to the PCM within the framework amid the charging prepare. The information procurement framework comprised of an array of K-type thermocouples (measured at $0.3 \%$ precision), a rotameter with a measuring precision of $0.02 \mathrm{l} / \mathrm{min}$, information lumberjack and personal computer framework to degree and record temperatures within the PCM and the mass flow rate of the heat transfer fluid.

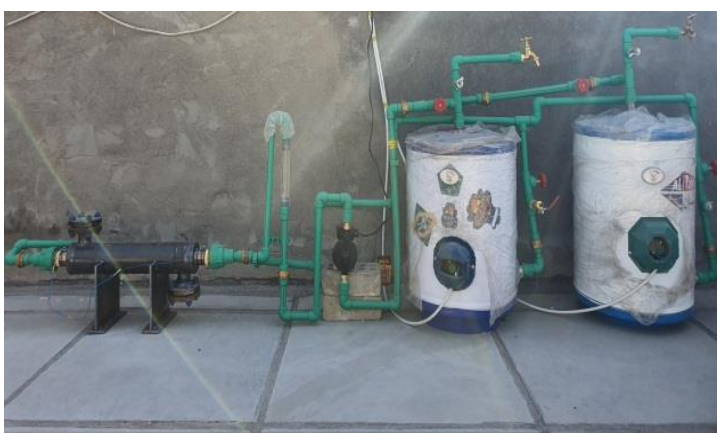

Figure 1. The experimental unit.

For the charging experiments, three different values for the inlet temperature of the water have been tested, which are all above the melting temperature of the paraffin under consideration: $\mathrm{Th}=70,75$ and $80{ }^{\circ} \mathrm{C}$. Flow rates were selected as $1 \mathrm{l} / \mathrm{min}$.

\subsection{Materials of Heat Storage}

In this study, Iraqi paraffin from Al- Doura refinery (Fig. 2) was used as a latent heat energy storage material. Iraqi paraffin is chemically stable, non-poisonous and non-corrosive over a large storage period, long life product, with stable performance through the phase change cycles. Table 1 depicts the thermos-physical properties the Iraqi paraffin.

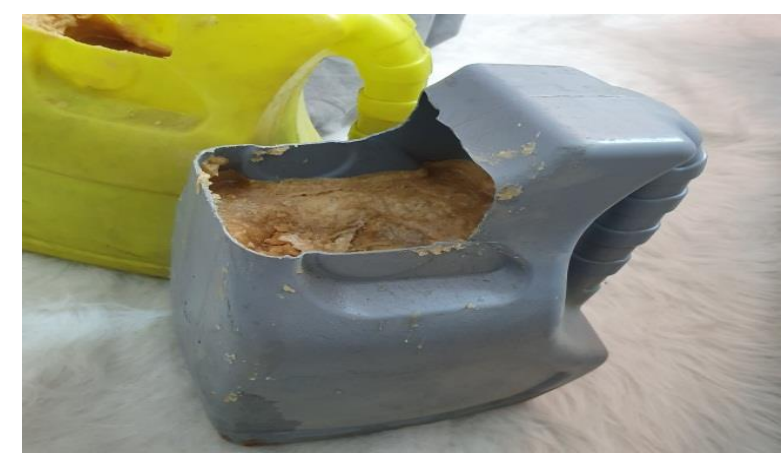

Figure 2. Iraqi paraffin from Al- Doura refinery

\subsection{Procedure}

Before the experimental runs, the heat exchanger was filled with $2 \mathrm{~kg}$ liquid PCM and no leakage was observed. A few runs were made in order to calibrate the system. A charging experiment was started in the morning, with the solid PCM at 
thermal equilibrium with the conditioned lab temperature $\left(23-25^{\circ} \mathrm{C}\right)$.

During the charging process, inlet HTF temperature was maintained at a set temperature using a PID controlled hot water bath. After an imposed $150 \mathrm{~min}$ of charge time, charging process was finished. Temperature readings were taken every $1 \mathrm{~min}$. Fig. 3 show the double pipe heat exchanger.

Table 1. Thermo-physical properties Iraqi paraffin.

\begin{tabular}{llc}
\hline property & Unit & Quantity \\
\hline Latent heat fusion & $\mathrm{KJ} / \mathrm{kg}$ & 194 \\
Melting point & ${ }^{\circ} \mathrm{C}$ & 41 \\
Solid paraffin density & $\mathrm{kg} / \mathrm{m} 3$ & 891 \\
Liquid paraffin density & $\mathrm{kg} / \mathrm{m} 3$ & 778 \\
Thermal Conductivity solid & $\mathrm{W} / \mathrm{m} .{ }^{\circ} \mathrm{C}$ & 0.22 \\
Thermal Conductivity liquid & $\mathrm{W} / \mathrm{m} .{ }^{\circ} \mathrm{C}$ & 0.15 \\
\hline
\end{tabular}

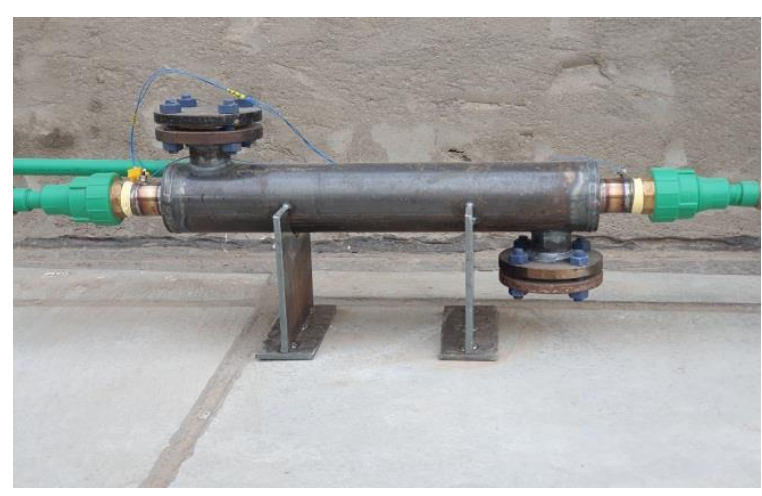

Figure 3. double pipe heat echanger.

\section{Results and discussion.}

The temperature distributions of PCMs in the storage tank for various mass flow rates, PCMs, and diameters of capsules are recorded during the charging and discharging processes.

\subsection{Effect of the flow rate of HTF and paraffin as PCM.}

Fig. 4 illustrates the effect of varying the mass flow rate of $\operatorname{HTF}(2,4$, and $6 \mathrm{~kg} / \mathrm{min})$ during the charging of the storage tank for the varying HTF inlet temperature. The graph shows that the flow rate of the HTF with varying HTF inlet temperature does not have a much significant influence on the charging time. Because the duration needed for charging is around $4 \mathrm{~h}$ (i.e., 10:00 a.m. to 2:00 p.m.), which is a long duration, the heat transfer rate influence from HTF to PCM is very low (5-10\%). This $10 \%$ variation is occurring due to the high heat transfer rate at the high HTF inlet temperature around 1:00 p.m. Figure 4 shows that the temperature of the TES system is reaching around $60{ }^{\circ} \mathrm{C}$ after 120 min (i.e., at12:00 p.m.). During this period the heat energy is stored in water and PCM in the form of sensible heat. At around $60{ }^{\circ} \mathrm{C}$, slope of the curves is nearer to being horizontal because heat is stored in the form of latent heat by melting the PCM. The slope of the curves from $65{ }^{\circ} \mathrm{C}$ to $70{ }^{\circ} \mathrm{C}$ is not high like the one at low temperatures around $40{ }^{\circ} \mathrm{C}$ because the difference between inlet HTF temperature and HTF temperature present in the storage tank is very low, so the time taken to raise the temperature from 65 to $70{ }^{\circ} \mathrm{C}$ is more.

\subsection{Effect of the Paraffin Mass as PCM}

Fig. 5 represents the variation of charging time and PCM (paraffin) temperature for different paraffin mass (2, 4 and 6) $\mathrm{kg}$.

The $2 \mathrm{~kg}$ paraffin mass charging time is less (around 10\%) compared to that of the $4 \mathrm{~kg}$ paraffin mass, and the PCM temperature is also more throughout the charging process compared to that of the $2 \mathrm{~kg}$ paraffin mass. Because the total surface area of the $2 \mathrm{~kg}$ paraffin mass around $70 \%$ more than that of the $4 \mathrm{~kg}$ paraffin mass and the internal heat resistance of the $2 \mathrm{~kg}$ paraffin mass is around $45 \%$ less than that of the $4 \mathrm{~kg}$ paraffin mass, the heat transfer rate will be faster between HTF and PCM in the $2 \mathrm{~kg}$ paraffin mass. In this experimental investigation the paraffin mass between 4 and $2 \mathrm{~kg}$ does not have much effect on the charging time because the heat 
source energy supply rate is much less even though the heat transfer rate from HTF to PCM is higher. It is observed that during the experiment from 10:00 a.m. to 1:00 p.m. (first three hours) the temperature of the inlet HTF increased from $30{ }^{\circ} \mathrm{C}$ to $65{ }^{\circ} \mathrm{C}$, i.e., in the charging process the difference in temperature between inlet HTF and PCM is not high.

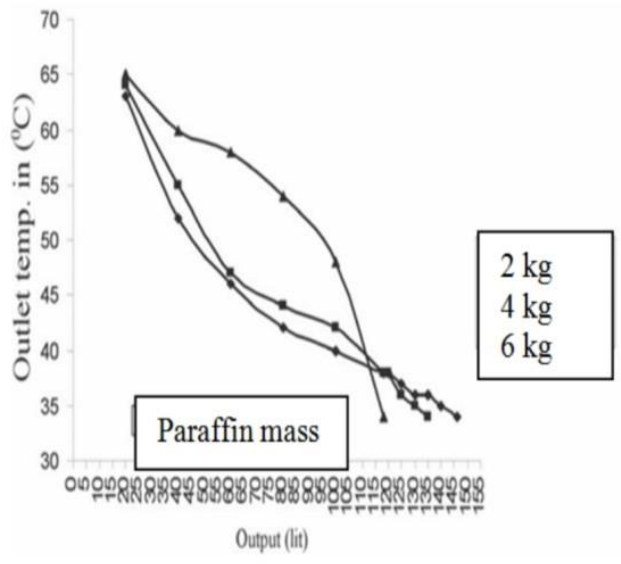

Figure 5. Variation of PCM temperature at $\mathrm{x} / \mathrm{l}$ for the different paraffin mass.

\section{Conclusions}

In the charging process using a varying heat source the results show that the different flow rates $(2,4$ and 6$) \mathrm{kg}$ of HTF does not have a much significant influence on the charging time. Because the duration for charging is around $4 \mathrm{~h}$ (i.e. 10:00 a.m. to 2:00 p.m.), which is a long duration, the heat transfer rate from HTF to PCM has a very low influence $(5-10 \%)$. For the discharging process there is no much difference in the quantity of thermal energy recovered in the batch wise discharge process for different flow rates $(2,4$ and 6) $\mathrm{kg}$ even though the quantities of hot water discharged are different. This is because in the $6 \mathrm{~kg}$ discharge flow rate the average temperature is high and the quantity is low, and in the case of $2 \mathrm{~kg}$ discharge flow rate the average temperature is low and the quantity is more correspondingly.

\section{Acknowledgements}

Thanks to the Department of Environmental Engineering for supporting this work.

\section{Conflict of Interest}

The authors declare that there are no conflicts of interest regarding the publication of this manuscript.

\section{Abbreviations}

TES Thermal Energy Storage

PCM Phase Change Material

HTF Heat Transfer Flow

LHTS Latent Heat Thermal Storage

\section{References}

1. Zalba, B., Marın, J.M., Cabeza, L.F. and Mehling, H. (2003). "Review on thermal energy storage with phase change: materials, heat transfer analysis and applications". Applied thermal engineering, 23(3), pp.251-283.

2. Farid, M.M., Khudhair, A.M., Razack, S.A.K. and Al-Hallaj, S. (2004). "A review on phase change energy storage: materials and applications". Energy conversion and management, 45(9-10), pp.1597-1615.

3. Khodadadi, J.M. and Zhang, Y. (2001). "Effects of buoyancy-driven convection on melting within spherical containers". International Journal of Heat and Mass Transfer, 44(8), pp.1605-1618.

4. Duan, Q., Tan, F.L. and Leong, K.C. (2002). "A numerical study of solidification of $n$ hexadecane based on the enthalpy formulation". Journal of materials processing technology, 120(1-3), pp.249258.

5. Khillarkar, D.B., Gong, Z.X. and Mujumdar, A.S. (2000). "Melting of a phase change material in concentric horizontal 
annuli of arbitrary cross-section". Applied Thermal Engineering, 20(10), pp.893-912.

6. Assis, E., Katsman, L., Ziskind, G. and Letan, R. (2007). "Numerical and experimental study of melting in a spherical shell". International Journal of Heat and Mass Transfer, 50(9-10), pp.1790-1804.

7. Assis, E., Ziskind, G. and Letan, R. ( 2009). "Numerical and experimental study of solidification in a spherical shell". Journal of Heat Transfer, 131(2).

8. Tan, F.L., Hosseinizadeh, S.F., Khodadadi, J.M. and Fan, L. (2009)." Experimental and computational study of constrained melting of phase change materials (PCM) inside a spherical capsule". International Journal of Heat and Mass Transfer, 52(15-16), pp.3464-3472.

9. Medrano, M., Yilmaz, M.O., Nogués, M., Martorell, I., Roca, J. and Cabeza, L.F. (2009). "Experimental evaluation of commercial heat exchangers for use as PCM thermal storage systems". Applied energy, 86(10), pp.2047-2055.
10. Seeniraj, R.V., Velraj, R. and Narasimhan, N.L., (2002). "Thermal analysis of a finnedtube LHTS module for a solar dynamic power system". Heat and mass transfer, 38(4), pp.409-417.

11. Vyshak, N.R., and Jilani, G. (2007). "Numerical analysis of latent heat thermal energy storage system". Energy conversion and management, 48(7), pp.2161-2168.

12. AL-Ataby, M.J.A. (2012). "Phase Change Materials for Thermal Energy Storage". Journal of Petroleum Research and Studies, 3(1), pp.69-92.

13. Alatabe, M.J.A. (2018). "Crystallization in phase change materials". International Journal of Scientific Research in Science, Engineering and Technology, 4(1), pp.9399. 